\title{
Simulation Based Analysis of Digitally Controlled 4-phase DC-DC Converter with Coupled Inductors
}

\author{
Kaspars Kroics \\ Institute of Physical Energetics, Laboratory of Power electronics. \\ Address: Aizkraukles street 21, Riga, Latvia, e-mail: kaselt@inbox.lv.
}

\begin{abstract}
Interleaved converters are used in many different conversion systems involving various topologies and are related to different fields of application due its advantages over single-phase converters. Such advantages include reduced current in switching devices and passive elements, reduced output current ripple, and so on. Reductions in size and costs of magnetic components and inductors current ripple can be achieved by an integration of magnetics. In this paper application of 2-phase coupled inductor designed in convenient way by using commercially manufactured coil formers and ferrite cores is analyzed to developed 4-phase interleaved DC-DC converter. Different structures of the coupled inductor for $\mathbf{4}$ phases is studied. The steady state phase and output current ripple in buck mode of the interleaving magnetic integrated bidirectional DC-DC converter is simulated. The necessary count of inductors for selected topology are manufactured and placed on the PCB board.
\end{abstract}

Keywords: DC-DC power converters, multiphase switching converters, integrated magnetic, bi-directional converter, digital control.

\section{INTRODUCTION}

Switching power converters have become more and more important in industry today. Interfacing the energy sources and storage devices such as fuel cells, batteries and supercapacitors requires several DC-DC conversion functions. In many applications such as photovoltaic arrays, fuel cells, wind generators high efficiency, small size DC-DC converter are required as an interface between the voltage source and the output loads, which operates at different voltage level.
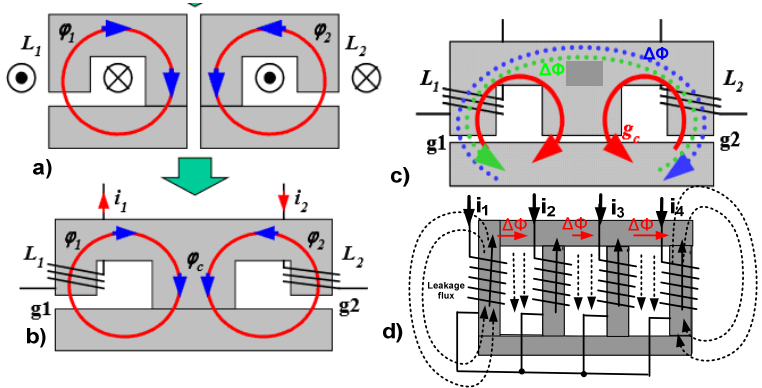

Fig. 1. Magnetic integration principle: a) single inductors; b) paralleled cores sharing a part of the core; c) increasing the coupling with gap in the central leg; d) multiphase magnetic integration

Single phase DC-DC converters have limitations in high current applications due to the redundant power loss in inductor and high inductor ripple current. The standard multiphase interleaved design avoids this problem because it achieves output current ripple cancelation. In the recent years energy transfer among phases by means of magnetic coupling has been used in multiphase converters [1-7]. Advantages of magnetic integration is improved dynamic behavior, size and losses of magnetic components and reduction of MOSFET stresses.

The geometric definition of the integrated cores can be done looking at the general principle of paralleling magnetic circuits (Fig. 1.). In Fig. 1a, two separate inductors with single gapped core is shown. The winding produces a magnetic flux through the magnetic circuit as shown by the arrows. In Fig. 1b, the cores of the inductors of different phases of an interleaved converter are split together, sharing a central leg. As magnetic resistance of the central leg is low, only a small part of magnetic flux goes throw the other winding. If air gap in central leg is introduced (Fig. 1c) then AC component of flux $(\Delta \Phi)$ goes through second winding and acts like a transformer reducing per-phase current ripple. The central leg have lower flux level and therefore the size of magnetic component can be reduced. If interleaved converter has many phases (Fig. 1d) then output current ripple is eliminated by interleaving and small inductance is necessary therefore magnetic leg for DC magnetic flux can be removed. 
Most of the prior scientific papers about coupling in multiphase converters is based on monolithic inter phase transformers similar to Fig. 1d. Such a transformer allows transferring energy among phases but for this transformer using of non standard cores is necessary. In this paper application of 2-phase coupled inductor designed in convenient way by using commercially manufactured coil formers and ferrite cores is analyzed to developed 4-phase interleaved DC-DC converter.

\section{MULTIPHASE INTERLEAVED CONVERTER APPROACH}

Interleaving control schemes are widely used in converter applications [8-12]. Merits of such control methods are reduction of input/output current and volume of the converter, increase in the processed power capacity of converters.

First look at the single phase converter. Current ripple of such a converter describes well known expression:

$$
\Delta I_{\text {one_phase }}=\frac{(1-D) \cdot V_{I N} D T}{L} .
$$

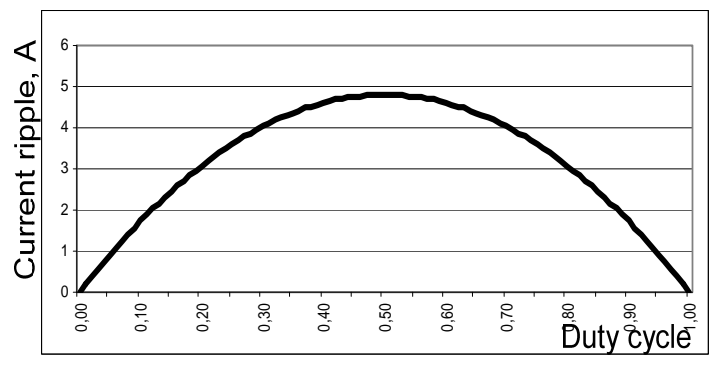

Fig. 2. Output current ripple of the single phase converter

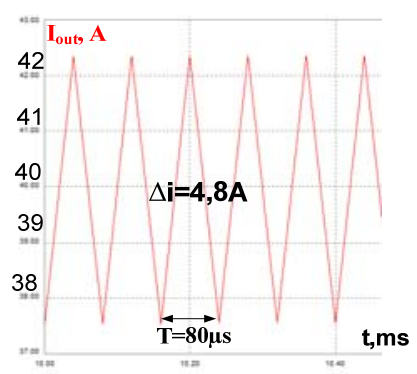

Fig. 3. Current of the single phase converter by $\mathrm{D}=0,5$

By using of the Eq. 1 can be drawn curve shown in Fig. 2. Can be seen that maximum current ripple is when duty cycle is equal to 0,5 . The particular curve is designed assuming that $\mathrm{V}_{\mathrm{IN}}=120 \mathrm{~V}, \mathrm{~L}=500 \mu \mathrm{H}$ and switching frequency of $12,5 \mathrm{kHz}$. Fig. 3 shows form of the current with maximum ripple by duty cycle equal to 0,5 . These curves will be used further to compare single phase solution with interleaved and interleaved with coupled inductor ones. The interleaving technique allows reducing of the output current ripple, reduction factor can be calculated as follows:

$\frac{\Delta I_{\text {multiphase }}}{\Delta I_{\text {one_phase }}}=\frac{N \cdot\left(D-\frac{m}{N}\right) \cdot\left(\frac{m+1}{N}-D\right)}{D \cdot(1-D)}$,

where D - duty cycle, $\mathrm{N}$ - number of phases and $\mathrm{m}=$ floor $(\mathrm{N} \cdot \mathrm{D})$ is the maximum integer that does not exceed $\mathrm{N} \cdot \mathrm{D}$ [14].

By using of the Eq. 2 can be drawn curve for particular four phase case shown in Fig. 4. By splitting together curve represented in Fig. 2 in relative units and calculated by Eq. 2 can be obtained viewable picture (Fig. 5) that allows comparing how interleaving allows to reduce output current ripple.

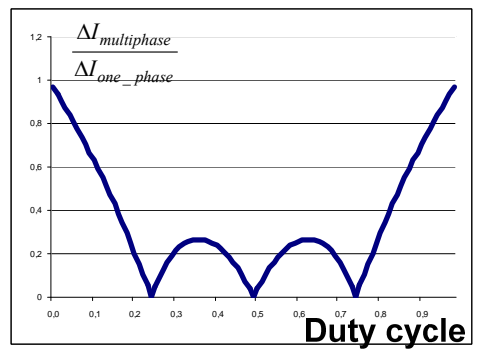

Fig. 4. Reduction factor of output current ripple of the four phase converter

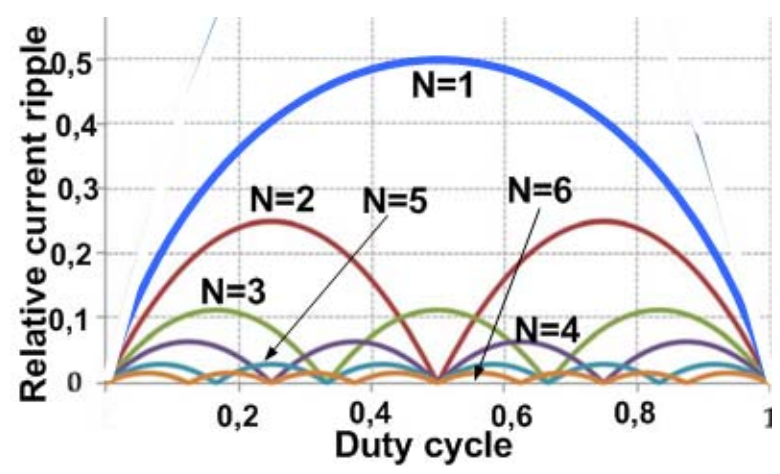

Fig. 5. Normalized output current ripple of the interleaved converter

Fig. 5 [13] shows the normalized output current ripple according to number of phases $(\mathrm{N})$ and duty cycle. It shows that by using interleaved structure current ripple can be significantly reduced. As can be seen from Fig. 5 interleaving of four phases reduces output current ripples in wide range therefore 4 phase boost converter structure is selected. Multiphase interleaved approach employing phase-shifted pulse width modulation (PWM) to control MOSFETs, it is often used in designs where paralleling of 
semiconductor devices is required. The phases are kept independent by using discrete inductors in each phase. Feature of the independent phase approach is the ability to turn-off the individual phases when the output power decreases, this allows maximization of the efficiency in each operating point.

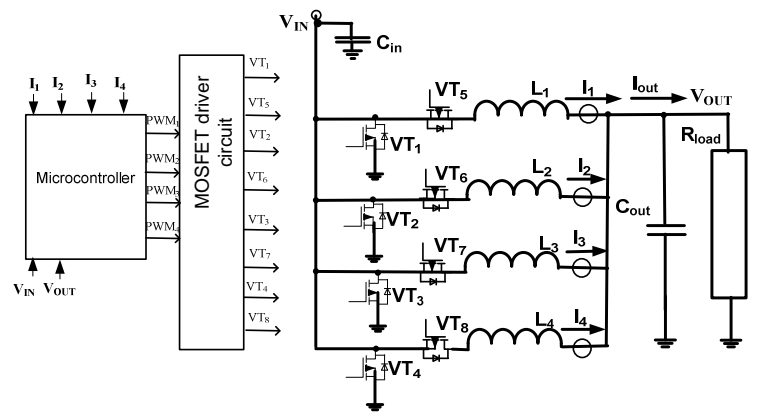

Fig. 6. The schematics of the interleaved DC-DC converter in buck mode with the uncoupled inductors

The prospective DC/DC converter will be provided for supercapacitor based energy storage system. Fig. 6 shows the structure of this bidirectional DC-DC converter. The transistors VT1 to VT8 is controlled by pulse width modulation. Each parallel pair of switches turns ON with shifting of 90 degrees. The switching frequency of the converter will be around $12,5 \mathrm{kHz}$. To control this DC/DC converter digital control will be used. Digital controllers of the previous era had bandwidth problems. In the recent years the situation has changed significantly. The speed and functionality performance of the microcontrollers has improved. They are also available at a much lower cost. The advantage of the digital controller is that it is programmable and offers more functionality to the system compared to the analog controllers. Novel control algorithms and methods with digital control can be realized. Such converter can be used for many other application, it can be modified as only buck or boost converter because synchronous rectification has better efficiency than diodes.

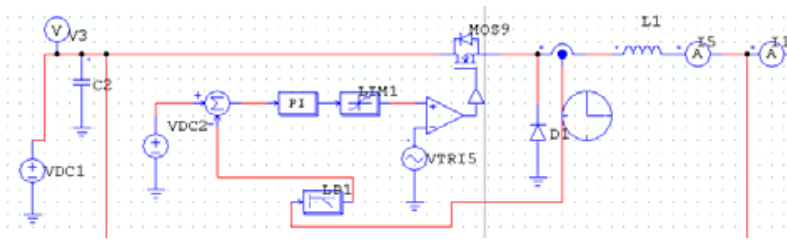

Fig. 7. The schematics of PSIM model for one phase of the interleaved DC-DC converter

For assessment of pulsation of current in for phase interleaved DC-DC converter PSIM model is used. Fig. 7. shows schematics of PSIM model for one phase of the converter. It consists of $120 \mathrm{~V}$ DC voltage source (VDC1), MOSFET transistor (MOS9), diode (D1), inductance $\mathrm{L}_{1}=0,5 \mathrm{mH}$, PI regulator which regulates average phase current equal to $10 \mathrm{~A}$.

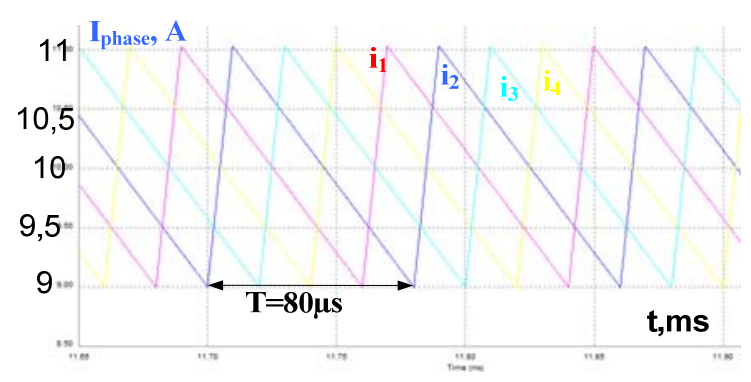

Fig. 8. Per-phase current in interleaved 4-phase DC-DC converter, $\mathrm{D}=0,125$

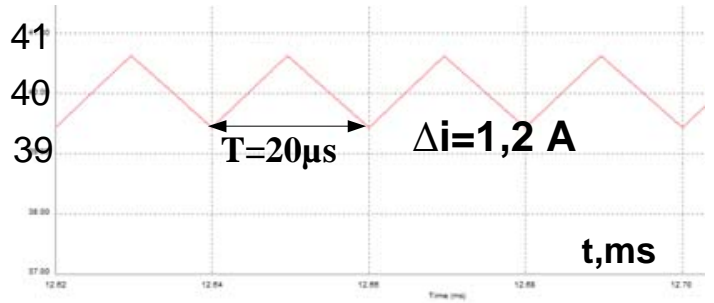

Fig. 9. Output current in interleaved 4-phase DC-DC converter, $\mathrm{D}=0,125$

Fig 8 and 9 shows results of the simulation by the duty cycle equal to 0,125 while then output current ripple is the biggest (Fig. 5). As can bee seen from figures pulsation of phase current is more significant than pulsation of output current. Ripple of output current is reduced at least 4 times and is less than 3 percent of the output current. Whereas per-phase current ripple stays high, it can be described by expression as follows:

$\Delta U_{\text {phase_uncoupled }}=\frac{\left(V_{I N}-V_{\text {out }}\right) D T}{L}=\frac{(1-D) V_{I N} D T}{L}$.

Eq. 3 matches with Eg.1 consequently Fig. 2 describes per-phase current ripple to. As follows from Fig. 2 the largest current ripple is when duty cycle is equal to 0,5 . Let us examine this case more detail by mean of simulation.

(Q) As can bee seen from Fig. 9 pulsation of phase current $(4,8 \mathrm{~A})$ is almost 50 percent of the total perphase current $(10 \mathrm{~A})$ and is much more larger than pulsation of output current (1,2 A). So big current ripple leads to increased losses in inductor and MOSFET transistors therefore interleaved converter with coupled inductor is useful because the significant advantage of interleaved converter with coupled inductor is that the ripple in one winding can be dumped to another winding and per-phase current ripple can be reduced. 


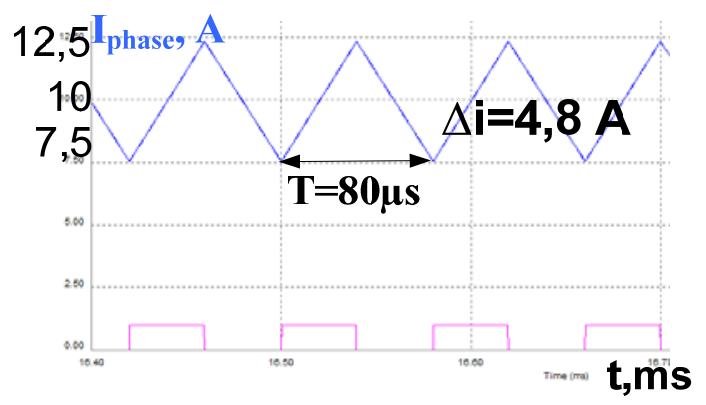

Fig. 9. Per-phase current in interleaved 4-phase DC-DC converter, $\mathrm{D}=0,5$

\section{PROPOSED COUPLED INDUCTOR}

The interleaving structure has more inductors than the single phase converter. The two individual inductors of the two interleaving channels can be integrated on a single magnetic core to reduce component size, per phase current ripple. The structure of the proposed integrated inductor is shown in Fig. 10. The both windings of the inductors is built on the central leg of the E core. Although in literature [1] is proposed to place windings of the inductor on the wing legs thereby obtaining higher leakage inductance, it is not available commercially manufactured coil formers for such a case. In this paper proposed inductor can be wound on ETD coil former in a convenient way. Figure 11 shows practical implementation of the coupled inductor of two phases. Winding of the one phase (2) and winding of the second phase (3) are separated by isolating material (1) and are placed on the coil former (4). The winding machine (5) can be used to build such an inductor.
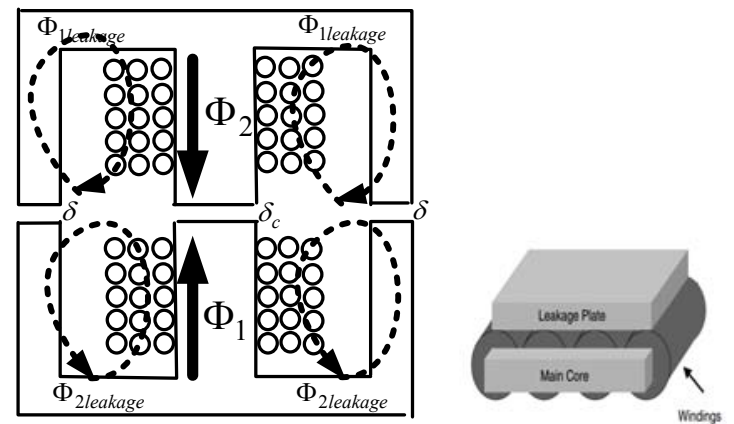

Fig. 10. Core structure of the coupled inductor and similar solution from $[14]$

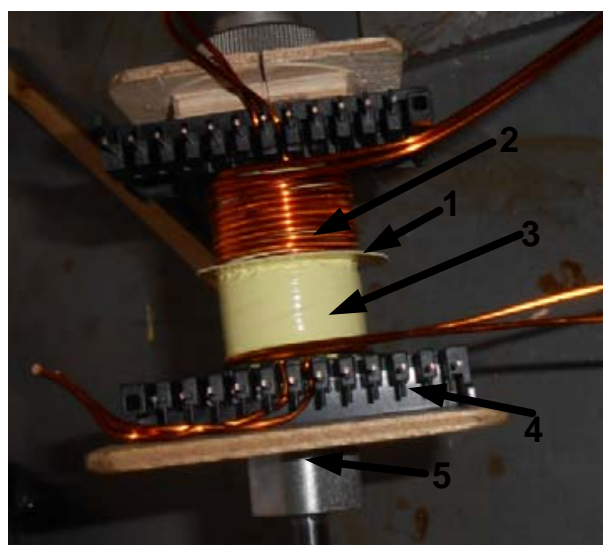

Fig. 11. Practical design of the coupled inductor

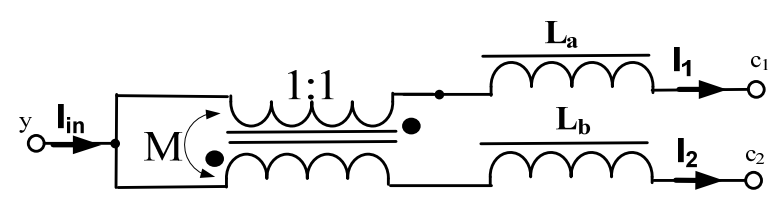

Fig. 12. Equivalent circuit of inversely coupled inductors

The equivalent circuit of a two-phase coupled inductor is shown in Fig. 12. The mutual inductance $\mathrm{M}$ represents the coupling between the two inductors. The voltages across the two inductors $\left(\mathrm{v}_{\mathrm{yc} 1}, \mathrm{v}_{\mathrm{yc} 2}\right)$ are related to the currents through them $\left(i_{1}, i_{2}\right)$ as follows:

$$
\begin{gathered}
v_{y c 1}=\left(L_{a}+M\right) \frac{d i_{1}}{d t}-M \frac{d i_{2}}{d t}, \\
v_{y c 2}=-M \frac{d i_{1}}{d t}+\left(L_{b}+M\right) \frac{d i_{2}}{d t} .
\end{gathered}
$$

Assuming that both inductors have the same inductance $\mathrm{L}_{\mathrm{a}}=\mathrm{L}_{\mathrm{b}}=\mathrm{L}_{\text {leakage, }} \mathrm{L}=\mathrm{M}+\mathrm{L}_{\text {leakage }}$ and by rearranging the equations (4) and (5):

$$
\frac{d i_{2}}{d t}=\frac{v_{y c 2}}{L}+\frac{M}{L} \frac{d i_{1}}{d t}
$$

As follows from equations 6 per phase current ripple of other phase affect first phase and in such a way current ripple of each phase can be reduced.

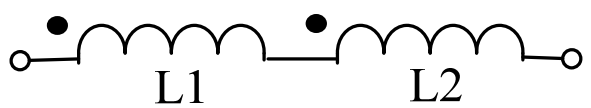

Fig. 13. Measuring of inductance

It is difficult to calculate precise value of inductance and coupling coefficient therefore easier is measure this values and change parameters of the inductor (air gaps, winding count) to achieve desired values. To measure coupling coefficient both 
windings must be connect in series and measured total inductance of this connection (Fig. 13). This inductance can be expressed as follows.

$$
L_{\text {total }}=L_{1}+L_{2}+2 M \text {. }
$$

If both of inductances is equal $\left(\mathrm{L}_{1}=\mathrm{L}_{2}=\mathrm{L}\right)$ then mutual inductance can be expressed as:

$$
M=\frac{L_{\text {total }}-2 L}{2} .
$$

Coupling coefficient is equal to:

$$
k=\frac{M}{L} .
$$

\section{SIMULATION AND ANALYSIS}

There are several implementation methods to build multiphase converter from two winding coupled inductor. The rule to generate a valid structure is that all the transformer lines must form at least a single line that includes all phases. Leakage inductance of all windings connected in the same phase can be considered as a single phase inductance that can help to filter the output voltage produced by the ideal transformer.

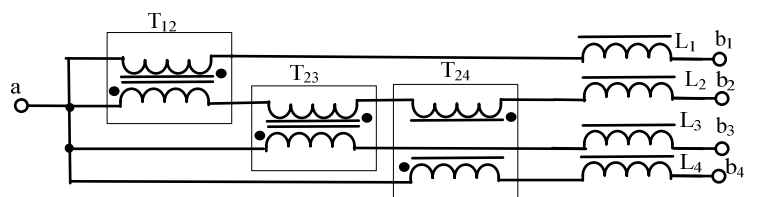

Fig. 14. Centralized structure of the coupled inductor for 4 phases

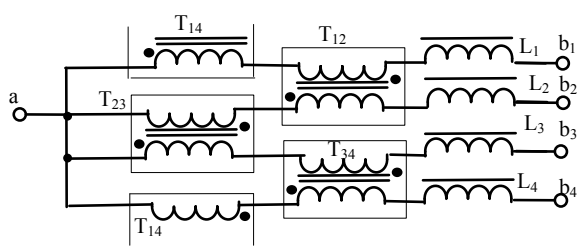

Fig. 15. Closed chain structure of the coupled inductor for 4 phases

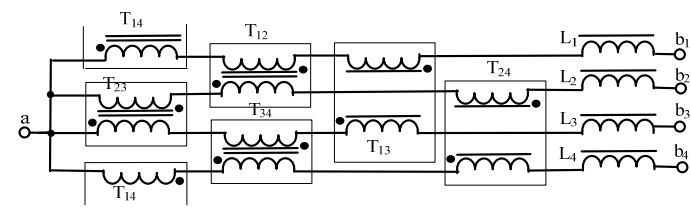

Fig. 16. Full matrix structure of the coupled inductor for 4 phases

Fig. 14, 15, 16 shows different structures to build 4phase interleaved converter with coupled inductor. In design of the proposed structures important are the number of transformers and volt-seconds applied to the transformer. The volt-seconds applied to the windings of the transformers reflects the way of transferring energy. If the energy is transferred more than once (centralized and closed chain structure), the higher the total losses of the transformer structure. From this point of view the best structure is full matrix but this structure needs more transformers therefore magnetic structure will be expensive with bigger volume. Centralized and closed chain structure have the same count of coupled inductors but centralized structure is not symmetrical so inductance of second phase will be larger and it leads to non symmetrical current in this phase therefore for closed chain structure is selected as most appropriate for particular case.

To assess the per-phase and output current ripple PSIM simulation of closed chain structure of coupled inductors with parameters equal to the developed inductor. In PSIM software is special element that simulates coupled inductor, they are connected in closed chain structure (Fig. 15) to simulate 4-phase interleaved DC-DC converter.

To view on integrated magnetic impression on current ripple reduction objectively magnetic flux must be taking in to account. As can bee seen in Fig. 10 through ferrite core flows magnetic flux that is generated by the current difference $\mathrm{i}_{1}-\mathrm{i}_{2}$ and DC component of current which creates leakage flux. Assuming the worst case when both currents of coupled inductor is in opposite phase then $i_{1}-i_{2}=2 \Delta I_{1}$. Taking this into account can be written equation for flux density B:

$B=\frac{L(1-k) \cdot I_{I N \_D C} / 4}{N A_{c}}+\frac{2 \Delta I_{1} L}{N A_{c}}$,

where $\mathrm{N}$ - number of turns; $\mathrm{A}_{\mathrm{c}}$ - core cross sectional area.

As can be seen from Eq. 10 flux density through core can be significantly reduced if coupling coefficient is equal to 1 , but increasing of coupling coefficient leads to the significant current ripple of output current therefore must be find some compromise between current ripple and flux density.

As for the core materials ferrite is used maximum flux density is set to $0,35 \mathrm{~T}$. If separate inductors is used then $5 \mathrm{~mm}$ air gap it is necessary to avoid saturation, by winding count 50 and the inductance is equal to $500 \mathrm{uH}$. If $\mathrm{k}=1$ then $\mathrm{M}=\mathrm{L}=5,6 \mathrm{mH}$, very small air gap is necessary but additional inductor is required to stay in the continues conduction mode and reduce output current ripple, the current regulator must be very advanced as current misbalance leads to saturation of the core of the transformer. In this case to avoid this problems coupling coefficient equal to 0,85 is selected with inductance of $400 \mu \mathrm{H}$. 


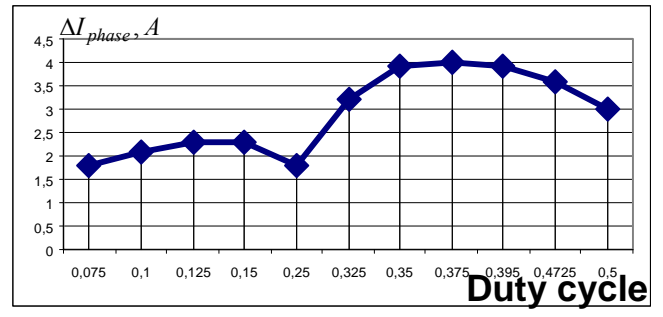

Fig. 17. Per-phase current ripple in 4-phase converter with coupled inductors

Per-phase current ripple of 4-phase interleaved DCDC converter with coupled inductors in cyclic cascade (Fig. 17) is less than in case with uncoupled inductors (Fig. 2). This curve is designed by simulation of the converter by different duty cycles, for example as displayed in Fig. 18. The form of the current is changing by different duty cycles.

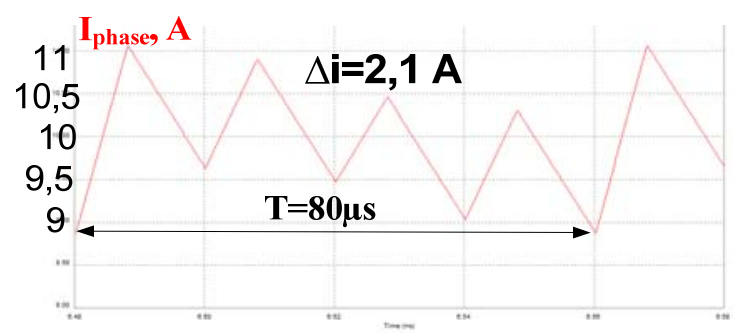

Fig. 28. Per-phase current ripple in 4-phase converter with coupled inductors, $\mathrm{D}=0,1$

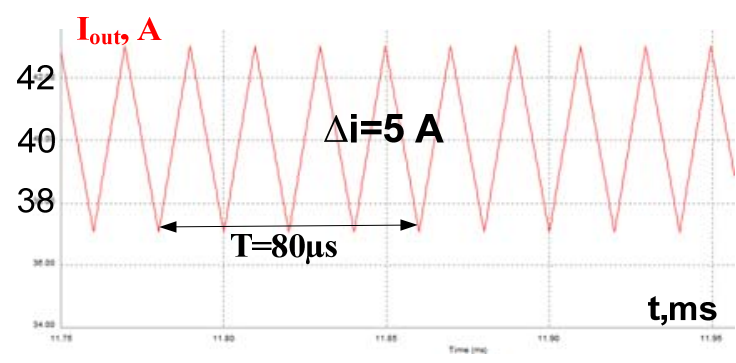

Fig. 19. Output current ripple in 4-phase converter with coupled inductors, $\mathrm{D}=0,125$ (max output current ripple)

Output core ripple in case of coupled inductor (Fig. 19) is higher than if uncoupled inductor is used (Fig. 9) and in particular converter is close to the one phase case (Fig. 2). Nevertheless, proposed structure allows reducing this current ripples by adding additional inductor in each phase or in the output branch to achieve desirable level of pulsations of output current.

\section{EXPERIMENTAL PROTOTYPE}

Four coupled inductors is made, they are placed on the board and connected in closed chain structure. It is necessary to complement with DSP, current sensors, MOSFET driver and so on to develop an operating interleaved DC-DC converter. Inductor is wound on ETD59 coil former, it structure is shown in
Fig. 3. The central air gap and air gaps of outer legs is selected equal to $\delta=\delta_{\mathrm{c}}=0,5 \mathrm{~mm}$, count of windings is 30 , the measured inductance is $\mathrm{L}=400 \mu \mathrm{H}$, coupling coefficient $\mathrm{k}=0,85$. In each phase there is two inductors in series.

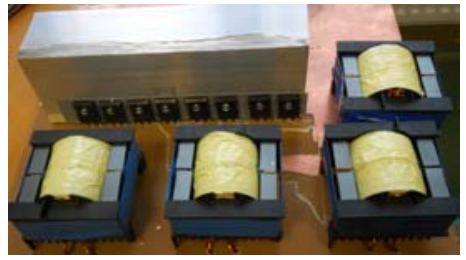

Fig. 20. Experimental prototype

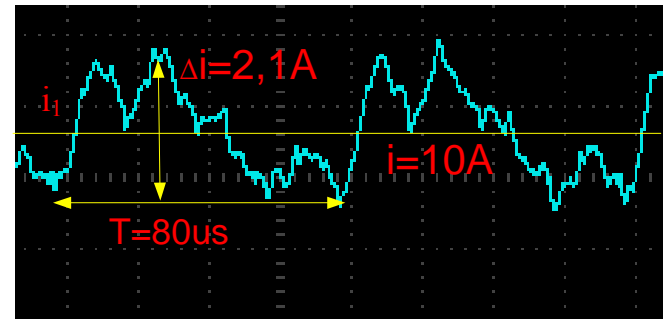

Fig. 21. Phase current, $\mathrm{D}=0,1$

Fig. 21 shows per-phase current of the experimental prototype, it is similar to the Fig. 18. This means that the simulation results are correct.

\section{CONCLUSIONS}

In this paper application of 2-phase coupled inductor designed in convenient way by using commercially manufactured coil formers and ferrite cores is analyzed to developed 4-phase interleaved DC-DC converter. The implementation approaches, operational principles and benefits are analyzed in detail based on simulation.

One of the main advantages of interleaved converters over single-phase converters is reduced output current ripple but per-phase current ripple remains large. Reductions this current ripple can be achieved by an integration of magnetics. Therefore original structure of two phase coupled inductor is proposed, it has constant inductance but moderate by air gap coupling coefficient, it can be designed by using traditional ETD core former.

Different structures of the coupled inductor for 4 phases DC-DC converter is studied and the closed chain structure is selected as the optimal solution. The phase and output current ripple in buck mode of the interleaving magnetic integrated converter is simulated. Simulation shows that per-phase ripple can be significantly reduced but output current ripple becomes a little bigger. If it is necessary, output current ripple can be reduced by using additional inductor. 


\section{ACKNOWLEDGMENTS}

This research work has been supported by Latvian Council of Science (Project Nr. 673/2014).

\section{REFERENCES}

[1] Pit-Leong W., Peng X., Yang P. Performance improvements of interleaving VRMs with coupling inductors, IEEE Trans. Power Electronics, Vol. 16, No. 4, 2001, pp. 499-507.

[2] Wong P. Performance Improvement Of Multi-Channel Interleaving Voltage Regulator Modules With Integrated Coupling Inductors, Ph.D. dissertation, Dept. Electr.Comput. Eng., Virginia Tech, Blacksburg, 2001.

[3] Zakis J., Husev O., Strzelecki R. Feasibility study of inductor coupling in three-level neutral-point-clamped quasi-Z-source DC/AC converter, Electric Power Quality and Supply Reliability Conference, 2014, pp. 273 - 276.

[4] Zhu G., Wang K. Modeling and design considerations of coupled inductor converters, Applied Power Electronics Conference and Exposition (APEC), 2010., pp.7-13.

[5] Lee P., Lee Y., Cheng D.., Liu X. Steady-state analysis of an interleaved boost converter with coupled inductors, Industrial Electronics, IEEE Transactions on , vol.47, no.4, 2000. pp.787-795.

[6] Santhos A., et al. Analysis of coupled inductors for low-ripple fast-response buck converter. IEICE transactions on fundamentals of electronics, communications and computer sciences vol. 92, no.2, 2009., pp. 451-455.
[7] Zumel P., et al. Tight magnetic coupling in multiphase interleaved converters based on simple transformers. Applied Power Electronics Conference and Exposition, 2005. APEC 2005. Twentieth Annual IEEE. Vol. 1., 2005., pp. 385 - 391.

[8] Ashur A. S., Thorn, R. Modeling and Simulation of Automotive Interleaved Buck Converter. Universities Power Engineering Conference, 2009, pp. 1-6.

[9] Chunliu C., Chenghua W. Research of an Interleaved Boost Converter with four Interleaved Boost Convert Cells. Microelectronics \& Electronics, 2009, pp. 396-399.

[10] Jin K., Yang M., Ruan X., Xu M., Three-Level Bidirectional Converter for Fuel-Cell/Battery Hybrid Power System. IEEE Trans. on Industrial Electronics, Vol. 57, No. 6, Jun. 2010, pp. 1976-1986.

[11] Carpita M., De Vivo M., Gavin S. A Bidirectional DC/DC interleaved converter for supercapacitor applications. Education and Research Conference (EDERC), 2012., pp.149, 153 .

[12] Grbović P., Delarue P., Le Moigne P., Bartholomeus P. A Bidirectional Three-Level DC-DC Converter for the Ultracapacitor Applications. IEEE Transactions on, Vol.57., No.10., 2010., pp. 3415-3430.

[13] Taylor R. PowerLab Notes: When to choose multiphase [online] [16.05.2014.]. Available at: http://goo.gl/KVfusd.

[14] Zimnik M. Multiphase buck converters [online] [12.02.2015.]. Available at: http://www.powerguru.org/multiphase-buckconverters/. 